OPEN ACCESS

Edited by:

Sajeewa S. N. Maharachchikumbura, University of Electronic Science and Technology of China, China

Reviewed by:

Dan Lawrence,

University of California, Davis, United States

Chada Norphanphoun,

Mae Fah Luang University, Thailand

*Correspondence:

Xinlei Fan

xinleifan@bjfu.edu.cn

Specialty section

This article was submitted to Plant Pathogen Interactions,

a section of the journal

Frontiers in Plant Science

Received: 01 December 2020

Accepted: 21 January 2021

Published: 18 February 2021

Citation:

Pan M, Zhu H, Tian C, Huang M and Fan X (2021) Assessment of Cytospora Isolates From Conifer

Cankers in China, With the Descriptions of Four New Cytospora Species. Front. Plant Sci. 12:636460. doi: $10.3389 /$ fpls. 2021.636460

\section{Assessment of Cytospora Isolates From Conifer Cankers in China, With the Descriptions of Four New Cytospora Species}

\author{
Meng Pan ${ }^{1}$, Haiyan Zhu ${ }^{1}$, Chengming Tian ${ }^{1}$, Manrong Huang ${ }^{2}$ and Xinlei Fan ${ }^{1 *}$ \\ 'The Key Laboratory for Silviculture and Conservation of Ministry of Education, Beijing Forestry University, Beijing, China, \\ ${ }^{2}$ Beijing Museum of Natural History, Beijing, China
}

Cytospora species are widely distributed and often occur as endophytes, saprobes or phytopathogens. They primarily cause canker and dieback diseases of woody host plants, leading to the growth weakness or death of host plants, thereby causing significant economic and ecological losses. In order to reveal the diversity of Cytospora species associated with canker and dieback diseases of coniferous trees in China, we assessed 11 Cytospora spp. represented by 28 fungal strains from symptomatic branches or twigs of coniferous trees, i.e., Juniperus procumbens, J. przewalskii, Picea crassifolia, Pinus armandii, P. bungeana, Platycladus orientalis in China. Through morphological observations and multilocus phylogeny of ITS, LSU, act, rpb2, tef1- $\alpha$, and tub2 gene sequences, we focused on four novel Cytospora species (C. albodisca, C. discostoma, C. donglingensis, and C. verrucosa) associated with Platycladus orientalis. This study represented the first attempt to clarify the taxonomy of Cytospora species associated with canker and dieback symptoms of coniferous trees in China.

Keywords: canker disease, coniferous trees, pathogen, phylogeny, taxonomy

\section{INTRODUCTION}

Coniferous trees are excellent landscaping species with a high ornamental and economic value. They are widely distributed as evergreen coniferous tree species and cultivated throughout China, except in Xinjiang and Qinghai Provinces (Ming, 2016). However, several coniferous trees are threatened by various pathogens in the process of planting and cultivation. Fan et al. (2020) reported five novel and one known Cytospora species causing canker and dieback diseases in conifers, with detailed descriptions and illustrations. Armillaria spp., Heterobasidion annosum, and Phellinus spp. have been reported to cause root and butt rot (Shaw and Kile, 1991; Hansen and Goheen, 2000). Moreover, leaf blight and Phytophthora diseases (Tucker and Milbrath, 1942; Phillips and Burdekin, 1992; Schlenzig et al., 2014) are also destructive to conifers.

Cytospora is one of the most important pathogenic fungi of hardwoods and coniferous trees with a worldwide distribution and large host range (Adams et al., 2005, 2006; Fan et al., 2014a,b, 2015a,b; Ariyawansa et al., 2015; Liu et al., 2015; Maharachchikumbura et al., 2015, 2016; Hyde et al., 2016; Li et al., 2016; Lawrence et al., 2017, 2018; Norphanphoun et al., 2017, 2018). Dieback and stem 
canker caused by Cytospora leads to the growth weakness or death of host plants, thereby causing significant economic and ecological losses (Adams et al., 2005). In conifers, Cytospora canker commonly occurs in the lowermost branches of mature trees, and stops spreading at the trunk (Adams et al., 2005). The asexual morph of Cytospora is characterized by the pycnidial stromata immersed in the bark with a single or multiple locule(s), with or without conceptacle. The conidia are aseptate, hyaline, allantoid, eguttulate, and smooth (Adams et al., 2005). The sexual morph is characterized by the ascomata immersed in the substrate with an erumpent pseudostroma, with or without necks. Asci are unitunicate, clavate to cylindrical. Ascospores are biseriate or multi-seriate, elongate-allantoid, thin-walled, hyaline, aseptate (Adams et al., 2005).

The taxonomy of the genus Cytospora is rather confusing. Ehrenberg (1818) established Cytospora and described four species simultaneously. Eighteen Cytospora species were proposed by Fries (1823), but the genus was recorded as Cytispora due to a misspelling. Thereafter, Saccardo (1884) revised the name to Cytospora and introduced 144 species. Due to the controversy in the corresponding relationship between sexual and asexual morphs, there were several synonyms, which had caused difficulties in the identification of Cytospora (Adams et al., 2005). Adams et al. (2005) officially reported that the sexual genera Leucocytospora, Leucostoma, Valsella, and Valseutypella are synonyms of Valsa. The traditional identification of Cytospora species is based heavily on their host affiliations. Nevertheless, the species occurrence may be related to geographical and environmental factors rather than host specificity (Fan et al., 2014a,b; Fan et al., 2015a,b). To more accurately identify Cytospora species, several species have been described based on morphological observations and multilocus phylogeny in recent studies (Yang et al., 2015; Lawrence et al., 2017, 2018; Zhu et al., 2018, 2020; Fan et al., 2020; Jiang et al., 2020; Shang et al., 2020). Norphanphoun et al. (2017) used four loci to describe 14 new species isolated from Rosa, Salix, and Sorbus. Lawrence et al. (2018) reported 15 Cytospora species that infected fruit trees and crops using a multiphasic approach. Pan et al. (2020) assessed 23 species of Cytospora associated with canker and dieback disease of Rosaceae members in China by six-locus phylogeny.

There are only a few relative taxonomic studies of Cytospora canker or dieback disease of conifers. Thus, there is an urgent need for studies to clarify the pathogens causing dieback and stem canker in coniferous trees. In this study, we aimed to reveal the diversity of Cytospora species associated with canker and dieback diseases of coniferous trees in China. As a part of an investigation of pathogens that cause canker or dieback disease in China, 28 Cytospora strains in coniferous trees with obvious symptoms were evaluated. Morphological characters in conjunction with multilocus phylogenetic analyses provided valuable information to identify the phylogenetic position of these isolates. Herein, we also introduced Cytospora albodisca, C. discostoma, C. donglingensis, and $C$. verrucosa as four new species with descriptions and illustrations, and compared them with other species in the genus.

\section{MATERIALS AND METHODS \\ Sample Collection and Isolation}

Fresh specimens with typical Cytospora fruiting bodies were collected from the infected twigs and branches of coniferous trees during collecting trips in China. A total of 12 isolates were obtained by removing a mucoid spore mass from conidiomata on the twigs and branches, spreading the suspension over the surface with standard potato dextrose agar (PDA) in a Petri dish, and incubating at $25^{\circ} \mathrm{C}$ for up to $24 \mathrm{~h}$. Single germinating conidia were transferred on to fresh PDA plates. All specimens and isolates were deposited in the Beijing Museum of Natural History (BJM) and the working Collection of X.L. Fan (CF) housed in Beijing Forestry University (BJFU). Axenic living cultures were deposited at China Forestry Culture Collection Centre (CFCC).

\section{Morphological Analyses}

Species identification was based on morphological characteristics of the ascomata or conidiomata produced on infected host materials. The macro-morphological characteristics including structure and size of stromata; the size, color, and shape of discs; number and diameter of ostioles per disc; presence and absence of conceptacle were determined under a Leica stereomicroscope (M205). The micro-morphological characteristics including size and shape of conidiophores and conidia were determined under a Nikon Eclipse 80i microscope equipped with a Nikon digital sight DS-Ri2 high-definition color camera with differential interference contrast (DIC). Over 10 ascomata/conidiomata were sectioned, and 10 asci and 30 ascospores/conidia were selected randomly for measurement. Colony morphology and growth rates were recorded and colony colors were described after 1 or 2 weeks according to the color charts of Rayner (1970). Adobe Bridge CS v.6 and Adobe Photoshop CS v. 5 were used for the manual editing. Taxonomic novelties and descriptions were deposited in MycoBank (Crous et al., 2004).

\section{DNA Extraction and PCR Amplification}

Genomic DNA was extracted using the modified CTAB method (Doyle and Doyle, 1990) from mycelium which was cultured on PDA with cellophane and obtained from the surface of cellophane by scraping. The extracted DNA were estimated visually by electrophoresis in $1 \%$ agarose gels by comparing band intensity with a DNA marker $1 \mathrm{kbp}$ (Takara Biotech). The qualities of DNA were measured with a NanoDrop ${ }^{\mathrm{TM}} 2000$ (Thermo, USA). Six loci including the internal transcribed spacer (ITS), the large nuclear ribosomal RNA subunit (LSU), the partial actin (act), the RNA polymerase II subunit ( $r p b 2)$, the translation elongation factor $1-\alpha(t e f 1-\alpha)$, and the beta-tubulin (tub2) genes were amplified and sequenced using the primer pairs ITS1 and ITS4 (White et al., 1990), LROR and LR7 (Vilgalys and Hester, 1990), ACT-512F and ACT-783R (Carbone and Kohn, 1999), RPB2-5F and fRPB2-7cR (Liu et al., 1999), EF-688F and EF1251R (Alves et al., 2008), and Bt-2a and Bt-2b (Glass and Donaldson, 1995). The PCR amplicons were electrophoresed in $2 \%$ agarose gels. DNA sequencing was carried out using an ABI PRISM ${ }^{\circledR}$ 3730XL DNA Analyzer with BigDye ${ }^{\circledR}$ Terminater Kit v.3.1 (Invitrogen) at the Shanghai Invitrogen Biological 
Technology Company Limited (Beijing, China). DNA sequences generated by the forward and reverse primers were used to obtain consensus sequences using Seqman v.9.0.4 (DNASTAR Inc., Madison, WI, USA).

\section{Phylogenetic Analyses}

The sequences generated from this study were analyzed with related Cytospora taxa which were obtained from GenBank and recent publications (Supplementary Table 1). To infer their phylogenetic relationship for the new sequences, the alignment based on ITS, LSU, act, $r p b 2$, tef1- $\alpha$, and tub2 sequence data was performed using MAFFT v.6 (Katoh and Standley, 2013) and edited manually using MEGA v.6.0 (Tamura et al., 2013). For individual sequences, some characters were excluded from both ends of the alignments to approximate the size of our sequences. The sequences of Diaporthe vaccinii (CBS 160.32) was included as outgroup in all analyses. Phylogenetic analyses were performed with PAUP v.4.0b10 for maximum parsimony (MP) (Swofford, 2003), MrBayes v.3.1.2 for Bayesian Inference (BI) (Ronquist and Huelsenbeck, 2003), and PhyML v.3.0 for maximum likelihood (ML) (Guindon et al., 2010).

MP analysis in PAUP v.4.0b10 was conducted using a heuristic search option of 1,000 random-addition sequences with treebisection-reconnection (TBR) as the branch-swapping algorithm (Swofford, 2003). The branches of zero length were collapsed using the command minbrlen, and all equally parsimonious trees were saved. Clade stability was assessed using a bootstrap (BT) analysis of 1,000 replicates (Hillis and Bull, 1993). Tree length (TL), consistency index (CI), retention index (RI), and rescaled consistency (RC) were calculated for all equally parsimonious trees. ML analysis in PhyML v.3.0 was performed with a general time reversible model (GTR) of site substitution following previous studies (Fan et al., 2020), including estimation of gamma-distributed rate heterogeneity and a proportion of invariant sites (Guindon et al., 2010). An evolutionary model for BI was estimated independently for each locus using MrModeltest v.2.3. The best-fit model was selected under the Akaike Information Criterion (AIC) (Posada and Crandall, 1998). BI analysis in MrBayes v.3.1.2 was done by a Markov Chain Monte Carlo (MCMC) algorithm with Bayesian posterior probabilities (BPP) (Rannala and Yang, 1996). Two MCMC chains started from random trees for 10 million generations, and trees were sampled each 100th generations. The first $25 \%$ of trees were discarded as the burn-in phase of each analysis, BPP were calculated to assess the remaining 7,500 trees (Rannala and Yang, 1996). Phylogram was viewed in Figtree v.1.3.1 (Rambaut and Drummond, 2010). All novel sequences derived from this study data were deposited in GenBank. The multigene sequence alignment files were deposited in TreeBASE (www.treebase.org; accession number: S27070).

\section{RESULTS}

A total of 12 Cytospora specimens were collected from symptomatic coniferous trees in China. The combined alignments matrix (ITS, LSU, act, rpb2, tef1- $\alpha$, and tub2) was used to clarify the phylogenetic position of these Cytospora species. Following alignment, the sequences for six loci comprised 231 Cytospora strains with Diaporthe vaccinii CBS 160.32 as the outgroup strain. The aligned matrix comprised 3,761 characters including gaps, of which 2,011 characters were constant, 258 variable characters were parsimony-uninformative, and 1,492 characters were variable and parsimony-informative. MP analysis generated 200 equally parsimonious trees with similar clade topologies, and one of which is presented in Figure $1(\mathrm{TL}=10402, \mathrm{CI}=0.300, \mathrm{RI}=0.799, \mathrm{RC}=0.239)$. For BI analyses, the best-fit model of nucleotide evolution was deduced on the AIC (ITS and act: GTR+I+G; LSU: $\operatorname{TrN}+\mathrm{I}+\mathrm{G} ; r p b 2$ and tef1- $\alpha: \operatorname{TrN}+\mathrm{I}+\mathrm{G}$; tub2: $\mathrm{HKY}+\mathrm{I}+\mathrm{G}) . \mathrm{ML}$ and Bayesian analyses did not significantly differ from MP tree. The MP bootstrap supports (MP-BS) and ML bootstrap (ML-BS) equal to or above 50\% were shown in branches in Figure 1. The branches with significant Bayesian posterior probabilities (BPP) equal to or above 0.95 were thickened in the phylogram. Based on the multigene phylogeny and morphology, the current 12 strains clustered in four clades were equivalent to four Cytospora species, were herein described as C. albodisca, C. discostoma, C. donglingensis, and C. verrucosa. All detailed descriptions and notes are below.

\section{Taxonomy}

\section{Cytospora albodisca M. Pan \& X.L. Fan, sp. nov. Figure 2}

MycoBank MB 837629

Typification: CHINA. Beijing City: Mentougou District, Mount Dongling, Xiaolongmen Forestry Centre, $115^{\circ} 28^{\prime} 28.52^{\prime \prime} \mathrm{E}$, $39^{\circ} 55^{\prime} 49.42^{\prime \prime} \mathrm{N}$, from branches of Platycladus orientalis, 17 August 2017, H.Y. Zhu \& X.L. Fan (holotype BJFC CF2019908, isotype BJM 240516), ex-type living culture CFCC 53161.

Etymology: Named after the white disc of ascostromata.

Descriptions: Sexual morph: Ascostromata immersed in the bark, erumpent through the surface of bark, scattered, immature, $580-910 \mu \mathrm{m}$ in diam. Conceptacle present. Ectostromatic disc beige to orange, circular, surrounded by dark ectostromatic tissue, with single ostiole in a disc, $220-375 \mu \mathrm{m}$ in diam. Ostioles single, white to pale yellow, at the same or below level as the disc, $90-150 \mu \mathrm{m}$ in diam. Perithecia beige with a little black when mature, flask-shaped to spherical, arranged irrugularly, $340-550 \mu \mathrm{m}$ in diam. Asci free, clavate to elongate-obovoid, $30-35 \times 6.5-8 \mu \mathrm{m}, 8$-spored. Ascospores uniserial, elongateallantoid, thin-walled, hyaline, aseptate, slightly rough, $8-14 \times$ $2-3.5$ (av. $=11.1 \pm 2.6 \times 2.6 \pm 0.3, n=30) \mu \mathrm{m}$. Asexual morph: On PDA, pycnidial stromata covered by abundant aerial mycelium, globose, solitary or aggregated deeply embedded in the medium, erumpent, dark green, $780-1,170 \mu \mathrm{m}$ in diam. Conidiophores cylindrical, thinner in the middle than the two ends, hyaline, unbranched, straight to slightly sinuous, 10.5$20.5 \times 1.5-2.5 \mu \mathrm{m}$. Conidiogenous cells enteroblastic, phialidic. Conidia hyaline, allantoid, occasionally with little curve, rough, aseptate, occasionally biguttulate, $5-7 \times 1-2$ (av. $=5.6 \pm 0.5 \times$ $1.4 \pm 0.2, n=30) \mu \mathrm{m}$.

Culture characteristics: Cultures on PDA are initially white, growing fast up to $7 \mathrm{~cm}$ in diam. after 3 days and entirely covering the $9 \mathrm{~cm}$ Petri dish after 5 days, becoming dark herbage green to dull green after 7-10 days. Colonies are sparse in the center and 


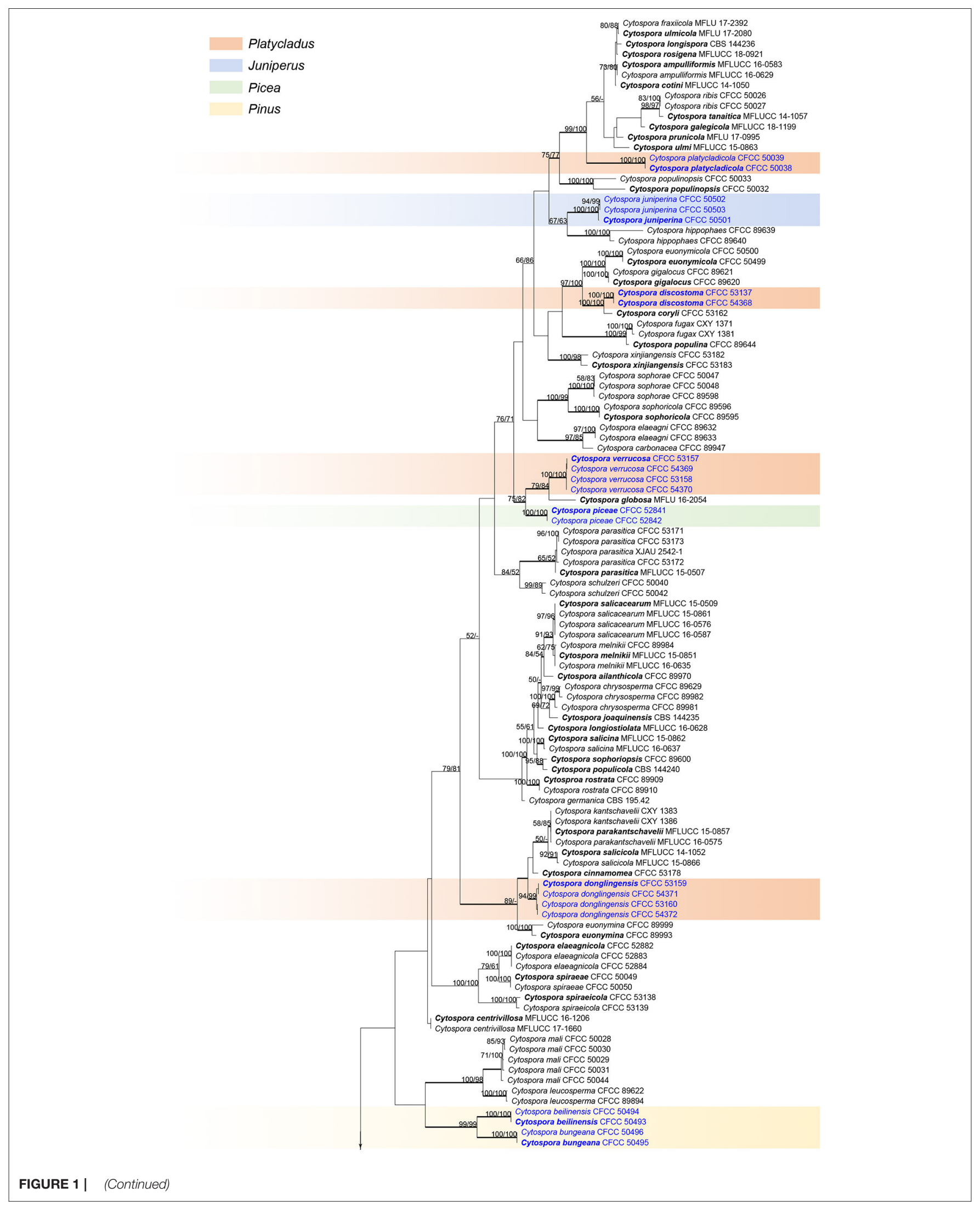




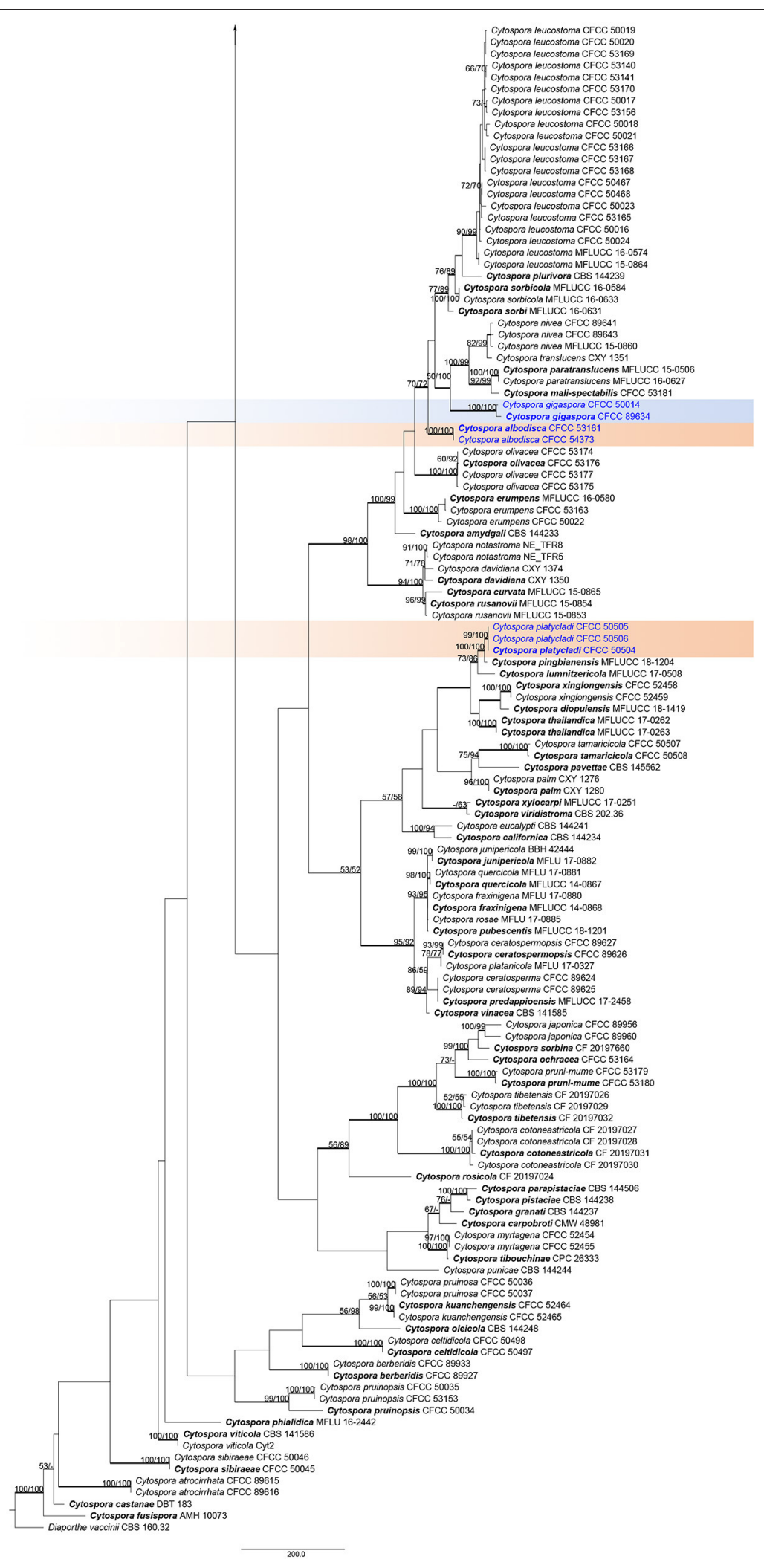

FIGURE 1 | Phylogram of Cytospora based on combined ITS, LSU, act, rpb2, tef1- $\alpha$, and tub2 genes. MP and ML bootstrap support values above $50 \%$ are shown at the first and second position. Thickened branches represent posterior probabilities above 0.95 from BI. Ex-type strains are in bold. Strains in current study are in blue. 

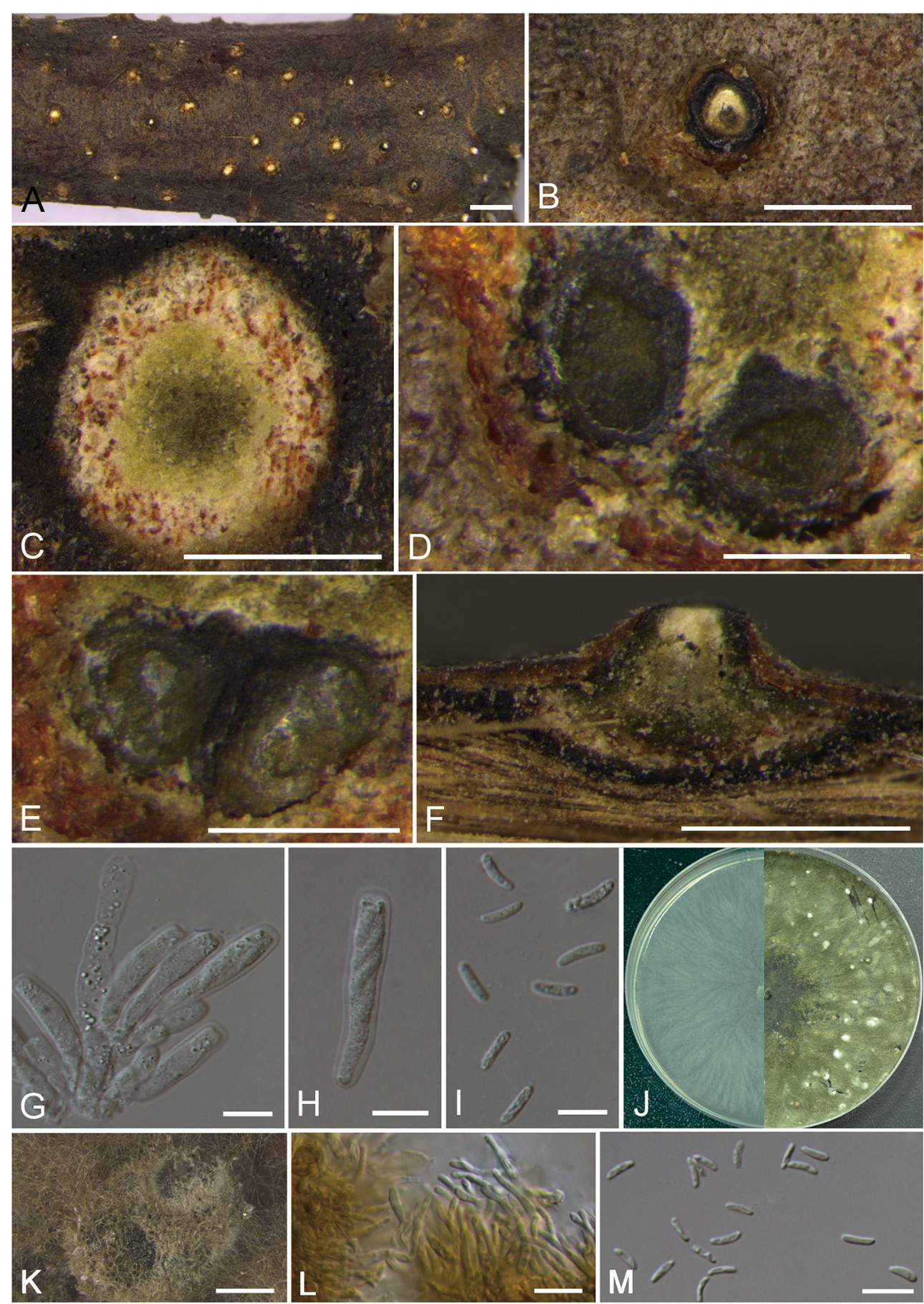

FIGURE 2 | Morphology of Cytospora albodisca (BJFC CF2019908). (A-C) Habit of ascomata on twig. (D,E) Transverse section of ascomata. (F) Longitudinal section through ascomata. (G) Asci and ascospores. (H) Ascus. (I) Ascospores. (J) Colonies on PDA at 3 days (left) and 30 days (right). (K) Conidiomata from culture

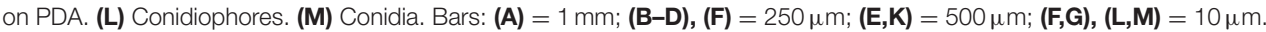

compact to the margin, felt-like. Pycnidia distributed irregularly on surface.

Additional material examined: CHINA. Beijing City: Mentougou District, Mount Dongling, Xiaolongmen Forestry Centre, $115^{\circ} 27^{\prime} 05.00^{\prime \prime} \mathrm{E}, 39^{\circ} 59^{\prime} 23.58^{\prime \prime} \mathrm{N}$, from branches of
Platycladus orientalis, 17 August 2017, H.Y. Zhu \& X.L. Fan (BJFC CF20201008), living culture CFCC 54373.

Notes: Cytospora albodisca is associated with canker disease of Platycladus orientalis in current study. It can be identified by having ascostroma surrounded by a black conceptacle, producing 
allantoid, aseptate ascospores $(8-14 \times 2-3.5 \mu \mathrm{m})$. Further, the two strains are phylogenetically separated from all other available strains included in this study. Based on DNA sequence data and morphology, therefore, we describe this species as new.

Cytospora discostoma M. Pan \& X.L. Fan, sp. nov. Figure 3

MycoBank MB 837632

Typification: CHINA. Beijing City: Mentougou District, Mount Dongling, Xiaolongmen Forestry Centre, $115^{\circ} 28^{\prime} 25.47^{\prime \prime} \mathrm{E}$, $39^{\circ} 56^{\prime} 48.57^{\prime \prime} \mathrm{N}$, from branches of Platycladus orientalis, 17 August 2017, H.Y. Zhu \& X.L. Fan (holotype BJFC CF2019802, isotype BJM 240517), ex-type living culture CFCC 53137.

Etymology: Named after the distinct disc of stromata on branches.

Descriptions: Sexual morph: not observed. Asexual morph: Pycnidial stromata discoid, immersed in the bark, scattered, erumpent through the surface of bark in a large area, with multiple locules and conspicuous central column. Central column beneath the disc more or less conical, pale gray. Conceptacle present. Ectostromatic disc gray to black, discoid, circular to ovoid, $210-320 \mu \mathrm{m}$ in diam., with a single ostiole per disc. Ostiole gray to black, nearly at the same level as the disc surface, $90-115 \mu \mathrm{m}$ in diam. Locules numerous, subdivided frequently by invaginations with common walls, circular to ovoid, 965-1050 $\mu \mathrm{m}$ in diam. Conidiophores hyaline, unbranched, approximately cylindrical, $14-18 \times 1-1.5 \mu \mathrm{m}$. Conidiogenous cells enteroblastic, phialidic. Conidia hyaline, elongate-allantoid, smooth, aseptate, 4.5-5.5 × 1-1.5 (av. $=4.9$ $\pm 0.3 \times 1.2 \pm 0.1, n=30) \mu \mathrm{m}$.

Culture characteristics: Cultures on PDA are initially white with hazel in the center, growing fast up to cover the $9 \mathrm{~cm}$ Petri dish after 3 days, becoming brown vinaceous after 7-10 days. Colonies are flat with a uniform texture. Pycnidia distributed irregularly on surface.

Additional material examined: CHINA. Beijing City: Mentougou District, Mount Dongling, Xiaolongmen Forestry Centre, $115^{\circ} 26^{\prime} 51.27^{\prime \prime} \mathrm{E}, 39^{\circ} 58^{\prime} 19.62^{\prime \prime} \mathrm{N}$, from branches of Platycladus orientalis, 17 August 2017, H.Y. Zhu \& X.L. Fan (BJFC CF20201002), living culture CFCC 54368.

Notes: This species is identified by having conidiomata with a column lenticular tissue in the center, and having
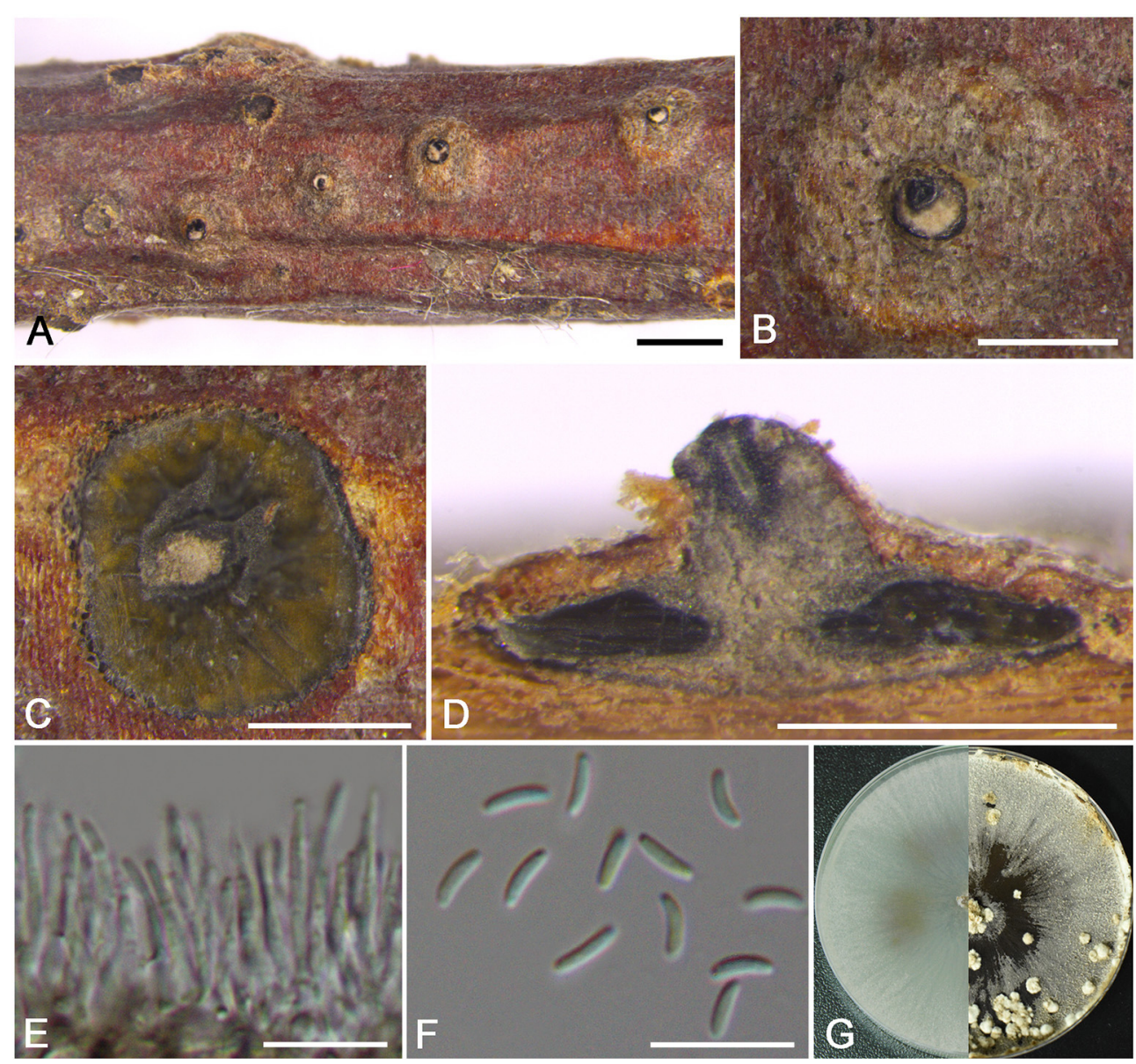

FIGURE 3 | Morphology of Cytospora discostoma (BJFC CF2019802). (A,B) Habit of conidiomata on twig. (C) Transverse section of conidioma. (D) Longitudinal section through conidioma. (E) Conidiophores and conidiogenous cells. (F) Conidia. (G) Colonies on PDA at 3 days (left) and 30 days (right). Bars: (A) = 1 mm; (B-D) $=500 \mu \mathrm{m} ;(\mathbf{E}, \mathbf{F})=10 \mu \mathrm{m}$. 
multiple locules surrounded by a black conceptacle. It can be distinguished from its closest relative $C$. coryli by the discoid pycnidial stromata with a conspicuous central column, and smaller conidia $(4.5-5.5 \times 1-1.5$ vs. $5-7 \times 1-2 \mu \mathrm{m})($ Zhu et al., 2020).

Cytospora donglingensis M. Pan \& X.L. Fan, sp. nov. Figure 4 MycoBank MB 837634

Typification: CHINA. Beijing City: Mentougou District, Mount Dongling, Xiaolongmen Forestry Centre, $115^{\circ} 26^{\prime} 47.36^{\prime \prime} \mathrm{E}$, $39^{\circ} 56^{\prime} 06.45^{\prime \prime} \mathrm{N}$, from branches of Platycladus orientalis, 17
August 2017, H.Y. Zhu \& X.L. Fan (holotype BJFC CF2019884, isotype BJM 240518), ex-type living culture CFCC 53159.

Etymology: Named after the location where it was collected, Mount Dongling.

Descriptions: Sexual morph: Ascostromata immersed in the bark, erumpent through the bark surface in a large area, scattered, with 5-8 perithecia arranged irregularly. Conceptacle absent. Ectostromatic disc buff, usually surrounded by ostiolar necks, triangular to circular, $550-900 \mu \mathrm{m}$ in diam., with $4-10$ ostioles arranged irregularly. Ostioles numerous, gray to black
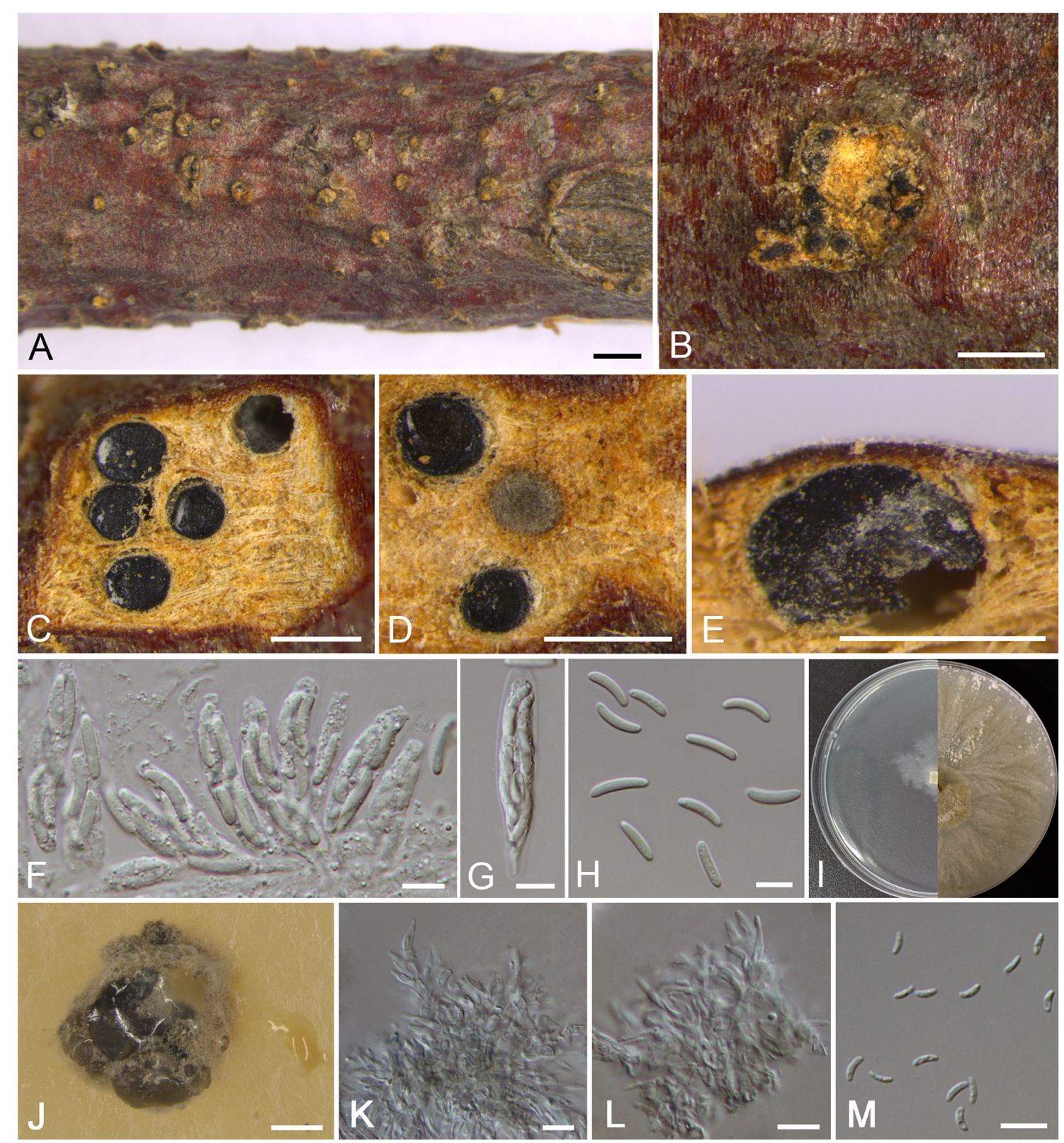

FIGURE 4 | Morphology of Cytospora donglingensis (BJFC CF2019884). (A,B) Habit of ascomata on twig. (C,D) Transverse section of ascomata. (E) Longitudinal section through ascomata. (F) Asci and ascospores. (G) Ascus. (H) Ascospores. (I) Colonies on PDA at 3 days (left) and 30 days (right). (J) Conidiomata from culture on PDA. (K,L) Conidiophores. (M) Conidia. Bars: (A) $=1 \mathrm{~mm}$; (B-E), (J) $=500 \mu \mathrm{m} ;(\mathbf{F}-\mathbf{H}),(\mathbf{K}-\mathbf{M})=10 \mu \mathrm{m}$. 
when mature, at the same or above level as the disc, arranged irregularly in a disc, $50-110 \mu \mathrm{m}$ in diam. Perithecia gray to black when mature, flask-shaped to spherical, arranged irrugularly, $310-380 \mu \mathrm{m}$ in diam. Asci hyaline, clavate to elongate-obovoid, 37.5-46.5 × 8-9.5 $\mu \mathrm{m}, 8$-spored. Ascospores hyaline, elongateallantoid, thin-walled, aseptate, $11-17 \times 2.5-4$ (av. $=13.8 \pm 1.4$ $\times 3 \pm 0.4, n=30) \mu \mathrm{m}$. Asexual morph: On PDA, pycnidial stromata covered by yellowish aerial mycelium, globose, solitary or aggregated deeply embedded in the medium, erumpent, black, $1,340-1,700 \mu \mathrm{m}$ in diam., yellowish translucent to cream conidial drops exuding from the ostioles. Conidiophores coniform with the top end acute, hyaline, branched, 13-19 × 1.5$3.5 \mu \mathrm{m}$. Conidiogenous cells enteroblastic, phialidic. Conidia hyaline, allantoid, occasionally with little curve, rough, aseptate, unconspicuous biguttulate, $4.5-6 \times 1-2$ (av. $=5.4 \pm 0.5 \times 1.5 \pm$ $0.2, n=30) \mu \mathrm{m}$.

Culture characteristics: Cultures on PDA are initially white, growing slowly up to $2 \mathrm{~cm}$ in diam. after 3 days and entirely covering the $9 \mathrm{~cm}$ Petri dish after 7 days, becoming straw after 7-10 days. Colonies are flat with a uniform texture, producing pycnidia covered by sparse aerial mycelium with cream to yellowish conidial drops exuding from the ostioles after 30 days. Pycnidia aggregated on surface.

Additional materials examined: CHINA. Beijing City: Mentougou District, Mount Dongling, Xiaolongmen Forestry Centre, $115^{\circ} 26^{\prime} 47.36^{\prime \prime} \mathrm{E}, 39^{\circ} 56^{\prime} 06.45^{\prime \prime} \mathrm{N}$, from branches of Platycladus orientalis, 17 August 2017, H.Y. Zhu \& X.L. Fan (BJFC CF20201084), living culture CFCC 54371. Beijing City: Mentougou District, Mount Dongling, Xiaolongmen Forestry Centre, $115^{\circ} 23^{\prime} 39.32^{\prime \prime} \mathrm{E}, \quad 39^{\circ} 57^{\prime} 13.43^{\prime \prime} \mathrm{N}$, from branches of Platycladus orientalis, 17 August 2017, H.Y. Zhu \& X.L. Fan (BJFC CF2019885), living culture CFCC 53160; ibid. BJFC CF20201085, living culture CFCC 54372.

Notes: In the phylogram, our new four isolates grouped in a separate clade with high statistical support $(\mathrm{MP} / \mathrm{ML} / \mathrm{BI}=$ 94/99/1) (Figure 1). Morphologically, C. donglingensis differs from other Cytospora species from Platycladus orientalis by the ascostroma without conceptacle, producing allantoid ascospores $(11-17 \times 2.5-4 \mu \mathrm{m})$. Thus, $C$. donglingensis is considered to represent a new species from Platycladus orientalis.

Cytospora verrucosa M. Pan \& X.L. Fan, sp. nov. Figure 5 MycoBank MB 837635

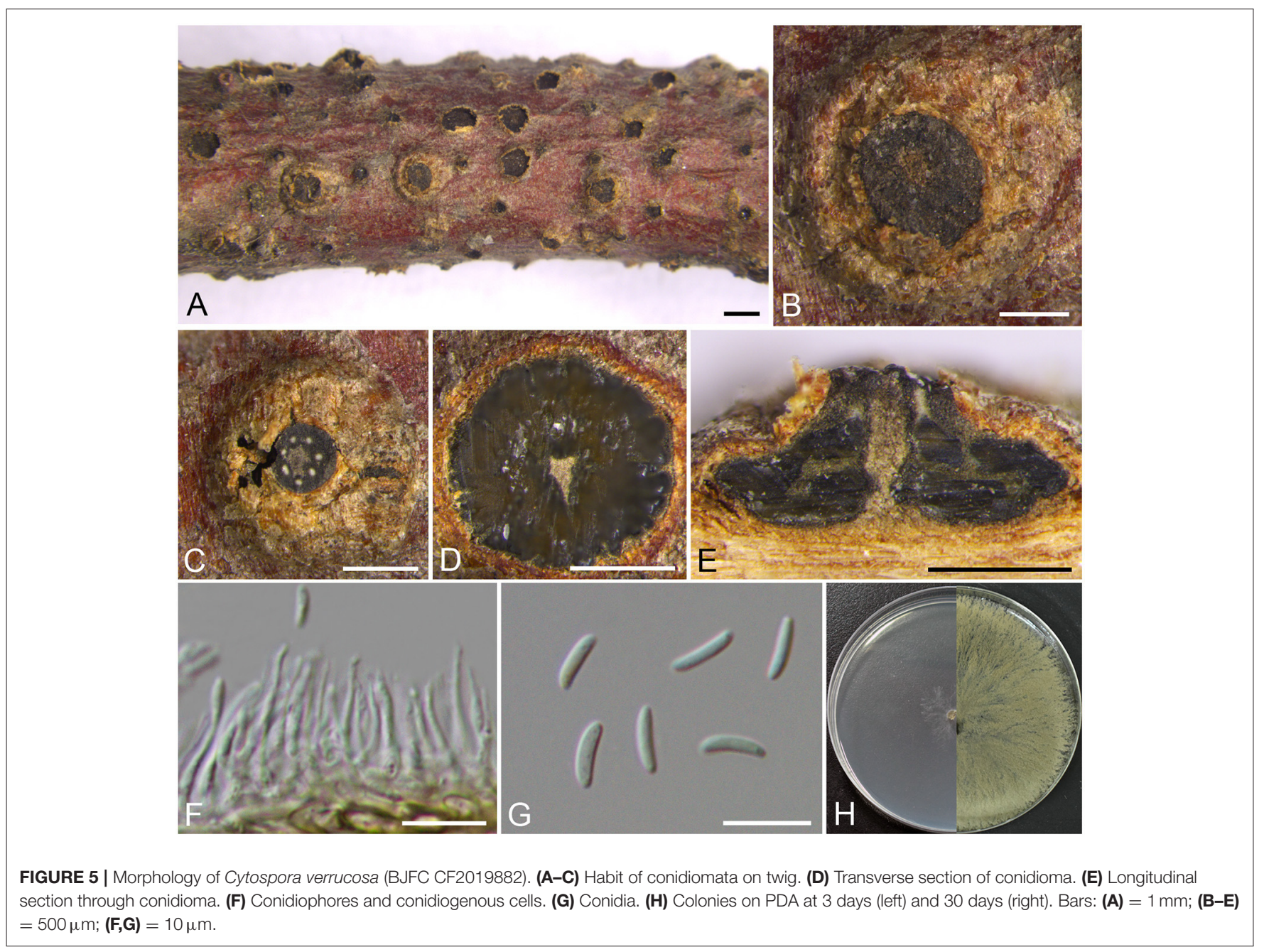


Typification: CHINA. Beijing City: Mentougou District, Mount Dongling, Xiaolongmen Forestry Centre, $115^{\circ} 26^{\prime} 38.25^{\prime \prime} \mathrm{E}$, $39^{\circ} 57^{\prime} 18.47^{\prime \prime} \mathrm{N}$, from branches of Platycladus orientalis, 17 August 2017, H.Y. Zhu \& X.L. Fan (holotype BJFC CF2019882, isotype BJM 240519), ex-type living culture CFCC 53157.

Etymology: Named after the verrucosa symptoms in branches. Descriptions: Sexual morph: not observed. Asexual morph: Pycnidial stromata immersed in the bark, scattered erumpent through the surface of bark in a large area, verrucosa, with multiple locules and conspicuous central column. Central column beneath the disc more or less cylindrical, ochreous. Conceptacle absent. Ectostromatic disc brown to black, circular to ovoid, erumpent through the surface of bark in a large area, unconspicuous when mature, $580-940 \mu \mathrm{m}$ in diam., with 5-7 ostioles per disc. Ostioles brown to black, arranged annularly on the disc, at the same or slightly above the level as the disc surface, $30-40 \mu \mathrm{m}$ in diam. Locules numerous, subdivided frequently by invaginations with common walls, $990-1,190 \mu \mathrm{m}$ in diam. Conidiophores approximately cylindrical with the top end acute, hyaline, unbranched, $10-13 \times 0.5-1.5 \mu \mathrm{m}$. Conidiogenous cells enteroblastic, phialidic. Conidia hyaline, allantoid, smooth, aseptate, $6.5-8 \times 1.5-2$ (av. $=7.3 \pm 0.4 \times 1.7 \pm 0.1, n=30) \mu \mathrm{m}$.

Culture characteristics: Cultures on PDA are initially white, growing up to $6 \mathrm{~cm}$ in diam. after 3 days and entirely covering the $9 \mathrm{~cm}$ Petri dish after 5 days, becoming buff to honey after 7-10 days. Colonies are flat with a uniform texture; sterile.

Additional materials examined: CHINA. Beijing City: Mentougou District, Mount Dongling, Xiaolongmen Forestry Centre, $115^{\circ} 26^{\prime} 38.25^{\prime \prime} \mathrm{E}, 39^{\circ} 57^{\prime} 18.47^{\prime \prime} \mathrm{N}$, from branches of Platycladus orientalis, 17 August 2017, H.Y. Zhu \& X.L. Fan (BJFC CF20201082), living culture CFCC 54369. Beijing City: Mentougou District, Mount Dongling, Xiaolongmen Forestry Centre, $115^{\circ} 27^{\prime} 23.07^{\prime \prime} \mathrm{E}, 39^{\circ} 58^{\prime} 26.37^{\prime \prime} \mathrm{N}$, from branches of Platycladus orientalis, 17 August 2017, H.Y. Zhu \& X.L. Fan (BJFC CF2019883), living culture CFCC 53158; ibid. BJFC CF20201083, living culture CFCC 54370.

Notes: Phylogenetically, our new four isolates cluster in a separate lineage $(\mathrm{MP} / \mathrm{ML} / \mathrm{BI}=100 / 100 / 1)$ comparing to other strains included in this study (Figure 1). Morphologically, $C$. verrucosa has similar characteristics to $C$. friesii, but it can be identified by having verrucosa symptoms in branches and pycnidia with a central column, and having numerous ostioles on a large area of the ectostromatic disc. Moreover, C. verrucosa differs from the closest species $C$. globosa by larger size of conidia $(6.5-8 \times 1.5-2$ vs. $4-6.5 \times 1-2 \mu \mathrm{m})$ (Li et al., 2020).

\section{Other Species Recorded From Coniferous Trees in China}

Cytospora beilinensis X.L. Fan \& C.M. Tian, Persoonia, 45: 14, 2020.

Notes: Cytospora beilinensis has been reported from twigs and branches of Pinus armandii by Fan et al. (2020) in China, which has the same host with C. pini (Saccardo, 1884). Morphologically, C. beilinensis has larger conidia compared to C. pini $(6-6.5 \times$ $1-1.5$ vs. $4 \times 1 \mu \mathrm{m})$ (Saccardo, 1884; Fan et al., 2020).
Cytospora bungeanae X.L. Fan \& C.M. Tian, Persoonia, 45: $15,2020$.

Notes: In this study, Cytospora beilinensis, C. bungeanae, and C. pini were associated with Pinus spp. Cytospora bungeanae is characterized by conidiomata with black and inconspicuous ostiole and numerous locules which arranged irregularly with individual walls (Fan et al., 2020). Cytospora bungeanae differs from $C$. beilinensis and $C$. pini by the conidia size $(4-5 \times 1$ vs. 6-6.5 × 1-1.5 $\mu \mathrm{m}, 4 \times 1 \mu \mathrm{m}$ ) (Saccardo, 1884; Fan et al., 2020).

Cytospora gigaspora C.M. Tian, X.L. Fan \& K.D. Hyde, Phytotaxa, 197: 232, 2015.

Notes: Cytospora gigalocus was recorded from Salix psammophila and Juniperus procumbens (Fan et al., 2015b, 2020), which was similar with $C$. nivea regarded as the pathogen for poplar and willow canker (Saccardo, 1884; Teng, 1963; Tai, 1979; Wei, 1979; Zhuang, 2005; Fan et al., 2014b). However, C. gigalocus differs from other Cytospora species by the flat locules and larger conidia size $(10.4 \times 2.2 \mu \mathrm{m})$ (Fan et al., 2015b).

Cytospora juniperina X.L. Fan \& C.M. Tian, Persoonia, 45: 27, 2020.

Notes: Cytospora juniperina was described by Fan et al. (2020) associated with canker disease of Juniperus przewalskii in China. It is characterized by $5-12$ perithecia arranged circularly or irregularly producing biseriate, elongate-allantoid, hyaline, aseptate ascospores $(10-13.5 \times 3-3.5 \mu \mathrm{m})$, and pycnidia with multiple locules producing allantoid, hyaline, aseptate conidia (6-6.5 × 1-1.5 $\mu \mathrm{m})($ Fan et al., 2020). Moreover, it has a unique characteristic owning a prominent white ectostromatic disc in symptomatic branches to easily diagnose.

Cytospora piceae Fan, Phytotaxa, 383: 188, 2018.

Notes: Cytospora piceae was described by Pan et al. (2018) associated with canker disease of Picea crassifolia in Xinjiang, China. Phylogenetically, C. piceae is closed to C. verrucosa and C. globosa. It can be distinguished from $C$. verrucosa by the absent of central column and larger conidia $(5-5.5 \times 1-1.5$ vs. $6.5-8 \times$ 1.5-2 $\mu \mathrm{m}$ ) (Pan et al., 2018). Cytospora piceae has a similar size of conidia with C. globosa, but C. piceae differs from C. globosa by larger conidiomata ( $720-1,190$ vs. $400-550 \mu \mathrm{m})$ and smaller ostiole (70-115 vs. 100-220 $\mu \mathrm{m}$ ) (Pan et al., 2018; Li et al., 2020).

Cytospora platycladi X.L. Fan \& C.M. Tian, Persoonia, 45: 33, 2020.

Notes: Cytospora platycladi was isolated from infected branches or twigs of Platycladus orientalis. Phylogenetically, $C$. platycladi formed a close group with C. lumnitzericola and $C$. pingbianensis. It differs from $C$. lumnitzericola by its disease symptoms with buff colored bark and the size of its conidia (4.5$5 \times 1-1.5$ vs. $4-5.5-1-1.3 \mu \mathrm{m}$ ) (Norphanphoun et al., 2018). It can also be distinguished from $C$. pingbianensis which is only introduced as a sexual morph by the phylogenetic position (Shang et al., 2020).

Cytospora platycladicola X.L. Fan \& C.M. Tian, Persoonia, 45: 33, 2020.

Notes: Cytospora platycladicola is associated with canker disease of Platycladus orientalis in China, which has same host with C. platycladi. Cytospora platycladicola can be distinguished from C. platycladi by the common walls of its locules (Fan et al., 2020). 


\section{Key to Cytospora species on Platycladus spp. in China}

1 Sexual morph present............... 2

1 Sexual morph absent............. 4

2 Ascostromata without conceptacle......... 3

2 Ascostromata with conceptacle.......... C. albodisca

3 Size of asci more than $47 \mu \mathrm{m}$........... C. platycladicola

3 Size of asci less than $47 \mu \mathrm{m}$.......... C. donglingsis

4 Pycnidium without conceptacle.......... 5

4 Pycnidium with conceptacle.......... C. discostoma

5 Pycnidial stromata with single ostiole............ C. platycladi

5 Pycnidial stromata with numerous ostioles............ C. verrucosa

\section{Key to Cytospora species on coniferous trees in China}

1 Sexual morph present............... 2

1 Sexual morph absent............ 5

2 Ascostromata without conceptacle............ 3

2 Ascostromata with conceptacle.............. C. albodisca

3 Size of asci more than $47 \mu \mathrm{m}$...... C. platycladicola

3 Size of asci less than $47 \mu \mathrm{m}$......... 4

4 Size of conidia more than $5.5 \mu \mathrm{m}$.......... C. juniperina

4 Size of conidia less than $5.5 \mu \mathrm{m}$........ C. donglingensis

5 Pycnidium without conceptacle......... 6

5 Pycnidium with conceptacle........... 10

6 Pycnidial stromata with single ostiole............ 7

6 Pycnidial stromata with numerous ostioles............ C. verrucosa

7 Locules with the common walls............ 8

7 Locules with the independent walls.............. C. platycladi

8 Host Pinus spp. .......... 9

8 Host Picea spp. ............ C. piceae

9 Size of conidia more than $5.5 \mu \mathrm{m}$.......... C. bungeanae

9 Size of conidia less than $5.5 \mu \mathrm{m}$.......... C. beilinensis

10 Pycnidial stromata without a central column... C. gigaspora

10 Pycnidial stromata with a central column... C. discostoma

\section{DISCUSSION}

In the present study, we utilized a polyphasic approach of molecular phylogenetic analyses of the combined alignment of ITS, LSU, act, rpb2, tef1- $\alpha$, and tub2 gene suquences along with morphological observations. Eleven Cytospora species represented by 28 strains from coniferous trees, including four new species (C. albodisca, C. discostoma, C. donglingensis, and C. verrucosa), and seven known species ( $C$. beilinensis, $C$. bungeanae, C. gigaspora, C. juniperina, C. piceae, C. platycladi, and C. platycladicola) were evaluated. A dubious species, $C$. curreyi, was reported from Abies sp. in the Sichuan Province, China (Teng, 1963), but it was not confirmed due to the nonavailability of living culture.

Consistent with the conclusions of a previous study, sexual morphs of Cytospora species associated with coniferous trees summarized herein are rarely found in nature. In the present study, among the specimens of the four new species, two new species (C. albodisca and C. donglingensis) had only sexual morphs, and the other two new species ( $C$. discostoma and $C$. verrucosa) had only asexual morphs. Therefore, we observed the asexual morphs of $C$. albodisca and $C$. donglingensis after sporulation on PDA medium. Adams et al. (2005) reported that the asexual morphs of Cytospora formed naturally may be different from those formed in culture, and these morphological characteristics may not be meaningful in classification. In conidia morphology, C. discostoma resembles $C$. donglingensis (4.5-5.5 $\times$ $1-1.5$ vs. $4.5-6 \times 1-2 \mu \mathrm{m})$. However, $C$. discostoma differs from C. donglingensis in ITS (33/656), LSU (7/522), act (61/367), rpb2 (71/726), tef1- $\alpha$ (104/824), and tub2 (101/648). We found that the size of the conidia was distinguishable from that of other species, and this was strongly supported by DNA sequence data.

Host affiliation has been primarily used as the delimitation in Cytospora in the early stage, and this has been proven uninformative because several Cytospora species have been discovered in a wide range of hosts (Adams et al., 2005, 2006; Lawrence et al., 2018; Norphanphoun et al., 2018; Fan et al., 2020; Pan et al., 2020). Lawrence et al. (2018) reported that Cytospora included generalist and specialist pathogens by taking C. chrysosperma and C. punicae as examples; however, a clear elucidation of the host ranges and distribution of Cytospora species will require a more exhaustive sampling of other coniferous trees from other regions of the world. Consistent with previous findings, some Cytospora species isolated from coniferous trees occurred on different hosts (i.e., $C$. ampulliformis, C. gigaspora, C. melnikii) (Fan et al., 2015b, 2020; Norphanphoun et al., 2017, 2018; Lawrence et al., 2018) rather than specific hosts. In addition, it cannot be denied that some species of Cytospora have a preference for certain hosts (i.e., $C$. japonica with chiefly Rosaceae host record, C. mali with apple host record and C. pini with pine host record) (Teng, 1963; Tai, 1979; Wei, 1979; Zhuang, 2005; Wang et al., 2011). In our study, all species with available strains found in China were associated with a single coniferous host (mainly Juniperus, Picea, Pinus, and Platycladus), with the exception of Cytospora gigaspora, which has also been reported in Salix psammophila (Fan et al., 2015b). These findings suggest that future studies are needed to better understand the interaction between fungi and their hosts.

Coniferous trees are the main timber and greening tree species in forestry production, but they are exposed to different pathogens. Cytospora was recorded on the hosts of four coniferous families (14 Cytospora spp. infecting Cupressaceae, 14 Cytospora spp. infecting Pinaceae, three Cytospora spp. infecting 
Taxaceae and three Cytospora spp. infecting Taxodiaceae) based on the U.S. National Fungus Collections Fungus-Host database (Farr and Rossman, 2021), but most species are inadequately identified and lack of molecular data. In China, some new species and new records of Cytospora on conifers have been reported successively (Fan et al., 2015b, 2020; Pan et al., 2018), lacking a systematic study summarizing Cytospora species isolated from conifers. The present study indicated that the common families of conifers infected by Cytospora are Cupressaceae and Pinaceae, although several coniferous hosts suffering from canker disease have not been discovered. Thus, the present research is preliminary in nature, and further studies using a more intensive and wider sampling of isolates are awaited.

Cytospora canker and dieback diseases present with different symptoms in hardwoods and conifers. In hardwoods, the symptoms are characterized by elongated, slightly sunken, and discolored areas in the bark with obvious black spots (Fan et al., 2020). However, discoloration of the adjacent cambium in conifers has not been observed, although the fungus can be isolated from nearby xylem (Schoeneweiss, 1983). A large amount of resin flows from the infected branches, covers the bark surface surrounded by the canker, and drips onto the lower branches (Schoeneweiss, 1983). Generally, in canker disease, Cytospora begins to infect through cracks and wounds in the bark. The wounds include pruning wounds, cold injuries, leaf scars, and branches with weakened shade. If perennial cankers originating from pruning wounds occur in places critical to the strength of the trees, they can be highly destructive (Biggs, 1989; Adams et al., 2006). Therefore, the occurrence of Cytospora canker and dieback diseases can be minimized by maintaining susceptible trees as strong as possible, and by removing dead and dying branches in the dry season. All unnecessary damage should be avoided. Moreover, the occurrence of Cytospora canker diseases is not only affected by the environment and distribution, but also by transmission (Fan et al., 2015b), which may act as potential inoculum sources for other hosts in natural and artificial environments. Six pathogens, including Cytospora, have been found to pose a high risk of causing severe damage if exported to other suitable environments (Cannon et al., 2016). At present, the host specificity and pathogenicity of several Cytospora species associated with coniferous trees are poorly known. In the subsequent studies, more attention should be

\section{REFERENCES}

Adams, G. C., Roux, J., and Wingfield, M. J. (2006). Cytospora species (Ascomycota, Diaporthales, Valsaceae): introduced and native pathogens of trees in South Africa. Aust. Plant Pathol. 35, 521-548. doi: 10.1071/AP06058

Adams, G. C., Roux, J., Wingfield, M. J., and Common, R. (2005). Phylogenetic relationships and morphology of Cytospora species and related teleomorphs (Ascomycota, Diaporthales, Valsaceae) from Eucalyptus. Stud. Mycol. $52,1-144$.

Alves, A., Crous, P. W., Correia, A., and Phillips, A. (2008). Morphological and molecular data reveal cryptic speciation in Lasiodiplodia theobromae. Fungal Divers. 28, 1-13.

Ariyawansa, H. A., Hyde, K. D., Jayasiri, S. C., Buyck, B., Chethana, K. W. T., Dai, D. Q., et al. (2015). Fungal diversity notes 111-252: taxonomic paid to the pathogenicity and aggressiveness of Cytospora, which can play a role in quarantine, monitoring, and early warning of forestry pathogen.

In conclusion, in this study, we focused on four Cytospora species isolated from Platycladus orientalis in China. Our study implies that many additional Cytospora species from China are still undiscovered. The keys to Cytospora species on Platycladus spp. and coniferous trees were established based on their unique morphological characteristics, and this will also help more extensive research on fungal pathogens in China. Furthermore, this study constitutes a step toward the taxonomic study of conifer pathogens, providing sustainable disease management strategies for conifers infected by Cytospora species in China.

\section{DATA AVAILABILITY STATEMENT}

The datasets presented in this study can be found in online repositories. The names of the repository/repositories and accession number(s) can be found in the article/Supplementary Material.

\section{AUTHOR CONTRIBUTIONS}

$\mathrm{XF}$ and CT: conceived and designed the experiments. MP, HZ, and $\mathrm{MH}$ : performed the experiments. MP and HZ: analyzed the data. MP: wrote the manuscript. XF: revised and approved the final version of the paper. All authors contributed extensively to the work presented in this paper.

\section{FUNDING}

This study is financed by the Fundamental Research Funds for the Central Universities (2019ZY23), the National Natural Science Foundation of China (31670647), and College Student Research and Career-creation Program of Beijing (S201910022007).

\section{SUPPLEMENTARY MATERIAL}

The Supplementary Material for this article can be found online at: https://www.frontiersin.org/articles/10.3389/fpls.2021. 636460/full\#supplementary-material 
Doyle, J. J., and Doyle, J. L. (1990). Isolation of plant DNA from fresh tissue. Focus $12,13-15$.

Ehrenberg, C. G. (1818). Sylvae Mycologicae Berolinenses. Berlin: Formis Teophili Bruschcke.

Fan, X. L., Bezerra, J. D. P., Tian, C. M., and Crous, P. W. (2020). Cytospora (Diaporthales) in China. Persoonia 45, 1-45. doi: 10.3767/persoonia.2020.45.01

Fan, X. L., Hyde, K. D., Liu, M., Liang, Y. M., and Tian, C. M. (2015a). Cytospora species associated with walnut canker disease in China, with description of a new species C. gigalocus. Fungal Biol. 119, 310-319. doi: 10.1016/j.funbio.2014.12.011

Fan, X. L., Hyde, K. D., Yang, Q., Liang, Y. M., Ma, R., and Tian, C. M. (2015b). Cytospora species associated with canker disease of three anti-desertification plants in northwestern China. Phytotaxa 197, 227-244. doi: 10.11646/phytotaxa.197.4.1

Fan, X. L., Liang, Y. M., Ma, R., and Tian, C. M. (2014a). Morphological and phylogenetic studies of Cytospora (Valsaceae, Diaporthales) isolates from Chinese scholar tree, with description of a new species. Mycoscience 55, 252-259. doi: 10.1016/j.myc.2013.10.001

Fan, X. L., Tian, C. M., Yang, Q., Liang, Y. M., You, C. J., and Zhang, Y. B. (2014b). Cytospora from Salix in northern China. Mycotaxon 129, 303-315. doi: $10.5248 / 129.303$

Farr, D. F., and Rossman, A. Y. (2021). Fungal Databases. U.S. National Fungus Collections, ARS, USDA, Washington, DC, United States.

Fries, E. M. (1823). Systema Mycologicum. Vol. 2. Greifswald: Sumtibus Ernesti Mauritti.

Glass, N. L., and Donaldson, G. C. (1995). Development of primer sets designed for use with the PCR to amplify conserved genes from filamentous ascomycetes. Appl. Environ. Microbiol. 61, 1323-1330. doi: 10.1128/AEM.61.4.1323-1330.1995

Guindon, S., Dufayard, J. F., Lefort, V., Anisimova, M., Hordijk, W., and Gascuel, H. O. (2010). New algorithms and methods to estimate maximum-likelihood phylogenies: assessing the performance of PhyML 3.0. Syst. Biol. 59, 307-321. doi: $10.1093 /$ sysbio/syq010

Hansen, E. M., and Goheen, E. M. (2000). Phellinus weirii and other native root pathogens as determinants of forest structure and process in western North America. Annu. Rev. Phytopathol. 38, 515-539. doi: 10.1146/annurev.phyto.38.1.515

Hillis, D. M., and Bull, J. J. (1993). An empirical test of bootstrapping as a method for assessing confidence in phylogenetic analyses. Syst. Biol. 42, 182-192. doi: $10.1093 /$ sysbio/42.2.182

Hyde, K. D., Hongsanan, S., Jeewon, R., Bhat, D. J., McKenzie, E. H. C., Gareth Jones, E. B., et al. (2016). Fungal diversity notes 367-490: taxonomic and phylogenetic contributions to fungal taxa. Fungal Divers. 80, 1-270. doi: 10.1007/s13225-016-0373-x

Jiang, N., Yang, Q., Fan, X. L., and Tian, C. M. (2020). Identification of six Cytospora species on Chinese chestnut in China. MycoKeys 62, 1-25. doi: $10.3897 /$ mycokeys.62.47425

Katoh, K., and Standley, D. M. (2013). MAFFT multiple sequence alignment software version 7: improvements in performance and usability. Mol. Biol. Evol. 30, 772-780. doi: 10.1093/molbev/mst010

Lawrence, D. P., Holland, L. A., Nouri, M. T., Travadon, R., Abramians, A., Michailides, T. J., et al. (2018). Molecular phylogeny of Cytospora species associated with canker diseases of fruit and nut crops in California, with the descriptions of ten new species and one new combination. IMA Fungus 9, 333-370. doi: 10.5598/imafungus.2018.09.02.07

Lawrence, D. P., Travadon, R., Pouzoulet, J., Rolshausen, P. E., Wilcox, W. F., and Baumgartner, K. (2017). Characterization of Cytospora isolates from wood cankers of declining grapevine in North America, with the descriptions of two new Cytospora species. Plant Pathol. 5, 713-725. doi: 10.1111/ppa.12621

Li, G. J., Hyde, K. D., Zhao, R. L., Hongsanan, S., Abdel-Aziz, F. A., AbdelWahab, M. A., et al. (2016). Fungal Divers notes 253-366: taxonomic and phylogenetic contributions to fungal taxa. Fungal Divers. 78, 1-237. doi: 10.1007/s13225-016-0366-9

Li, W. J., McKenzie, E. H. C., Liu, J. K., Bhat, D. J., Dai, D. Q., Camporesi, E., et al. (2020). Taxonomy and phylogeny of hyaline-spored coelomycetes. Fungal Divers. 100, 279-801. doi: 10.1007/s13225-020-00440-y

Liu, J. K., Hyde, K. D., Jones, E. B. G., Ariyawansa, H. A., Bhat, D. J., Boonmee, S., et al. (2015). Fungal Diversity Notes 1-110: taxonomic and phylogenetic contributions to fungal species. Fungal Divers. 72, 1-197. doi: 10.1007/s13225-015-0324-y

Liu, Y. L., Whelen, S., and Hall, B. D. (1999). Phylogenetic relationships among ascomycetes: evidence from an RNA polymerase II subunit. Mol. Biol. Evol. 16, 1799-1808. doi: 10.1093/oxfordjournals.molbev. a026092

Maharachchikumbura, S. S. N., Hyde, K. D., Jones, E. B. G., McKenzie, E. H. C., Bhat, J. D., Dayarathne, M. C., et al. (2016). Families of Sordariomycetes. Fungal Divers. 79, 1-317. doi: 10.1007/s13225-0160369-6

Maharachchikumbura, S. S. N., Hyde, K. D., Jones, E. B. G., McKenzie, E. H. C., Huang, S. K., Abdel-Wahab, M. A., et al. (2015). Towards a natural classification and backbone tree for Sordariomycetes. Fungal Divers. 72, 199-301. doi: 10.1007/s13225-015-0331-z

Ming, J. (2016). Biological Characteristics of Huangdi Mausoleum Platycladus Orientalis Leaf Wilt and Inhibitory Effects of Fungicides. Shaanxi: Northwest A and F University.

Norphanphoun, C., Doilom, M., Daranagama, D. A., Phookamsak, R., Wen, T. C., Bulgakov, T. S., et al. (2017). Revisiting the genus Cytospora and allied species. Mycosphere 8, 51-97. doi: 10.5943/mycosphere/8/1/7

Norphanphoun, C., Raspun, C., Jeewon, R., Wen, T. C., and Hyde, K. D. (2018). Morphological and phylogenetic characterisation of novel Cytospora species associated with mangroves. MycoKeys 38, 93-120. doi: 10.3897/mycokeys.38.28011

Pan, M., Zhu, H. Y., Guido, B., Tian, C. M., and Fan, X. L. (2020). High diversity of Cytospora associated with canker and dieback of Rosaceae in China, with ten new species described. Front. Plant Sci. 11:690. doi: 10.3389/fpls.2020. 00690

Pan, M., Zhu, H. Y., Tian, C. M., Alvarez, L. V., and Fan, X. L. (2018). Cytospora piceae sp. nov. associated with canker disease of Picea crassifolia in China. Phytotaxa 383, 181-196. doi: 10.11646/phytotaxa.383.2.4

Phillips, D. H., and Burdekin, D. A. (1992). Disease of Forest and Ornamental Trees. London: Macmillan. doi: 10.1007/978-1-349-10953-1

Posada, D., and Crandall, K. A. (1998). Modeltest: testing the model of DNA substitution. Bioinformatics 14, 817-818. doi: 10.1093/bioinformatics/14. 9.817

Rambaut, A., and Drummond, A. (2010). FigTree v.1.3.1. Edinburgh: Institute of Evolutionary Biology. University of Edinburgh.

Rannala, B., and Yang, Z. (1996). Probability distribution of molecular evolutionary trees: a new method of phylogenetic inference. J. Mol. Evol. 43, 304-311. doi: 10.1007/BF02338839

Rayner, R. W. (1970). A Mycological Colour Chart. Kew: Commonwealth Mycological Institute.

Ronquist, F., and Huelsenbeck, J. P. (2003). MrBayes 3: Bayesian phylogenetic inference under mixed models. Bioinformatics 19, 1572-1574. doi: 10.1093/bioinformatics/btg180

Saccardo, P. A. (1884). Sylloge Fungorum 3: i-ii. Padua: Typis Seminarii.

Schlenzig, A., Campbell, R., and Eden, R. (2014). First report of Phytophthora lateralis on Chamaecyparis pisifera. New Dis. Rep. 29:15. doi: 10.5197/j.2044-0588.2014.029.015

Schoeneweiss, D. F. (1983). Drought predisposition to Cytospora canker in blue spruce. Plant Dis. 67, 383-385. doi: 10.1094/PD-67-383

Shang, Q. J., Hyde, K. D., Camporesi, E., Maharachchikumbura, S. S. N., Norphanphoun, C., Brooks, S., et al. (2020). Additions to the genus Cytospora with sexual morph in Cytosporaceae. Mycosphere 11, 189-224. doi: $10.5943 /$ mycosphere/11/1/2

Shaw, C. G., and Kile, G. A. (1991). Armillaria Root Disease. Agricultural Handbook No. 691. Washington, DC: United States department of Agriculture.

Swofford, D. L. (2003). PAUP*: Phylogenetic Analysis Using Parsimony (*and other methods) version 4.0b10. Sunderland: Sinauer Associates.

Tai, F. L. (1979). Sylloge Fungorum Sinicorum. Beijing: Science Press.

Tamura, K., Stecher, G., Peterson, D., Filipski, A., and Kumar, S. (2013). MEGA 6: molecular evolutionary genetics analysis version 6.0. Mol. Biol. Evol. 30, 2725-2729. doi: 10.1093/molbev/mst197

Teng, S. C. (1963). Fungi of China. Beijing: Science Press.

Tucker, C. M., and Milbrath, J. A. (1942). Root rot of Chamaecyparis by a species of Phytophthora. Mycologia 34, 94-101. doi: 10.1080/00275514.1942.12 020875 
Vilgalys, R., and Hester, M. (1990). Rapid genetic identification and mapping of enzymatically amplified ribosomal DNA from several Cryptococcus species. J. Bacteriol. 172, 4238-4246. doi: 10.1128/JB.172.8.4238-42 46.1990

Wang, X. L., Kang, Z. S., Huang, L. L., and Wei, J. (2011). Re-evaluation of pathogens causing Valsa canker on apple in China. Mycologia 103, 317-324. doi: $10.3852 / 09-165$

Wei, J. C. (1979). Identifcation of Fungus Handbook. Shanghai: Science Press.

White, T. J., Bruns, T., Lee, S., and Taylor, J. (1990). Amplification and direct sequencing of fungal ribosomal RNA genes for phylogenetics. PCR Protocols 18, 315-322. doi: 10.1016/B978-0-12-372180-8.50042-1

Yang, Q., Fan, X. L., Crous, P. W., Liang, Y. M., and Tian, C. M. (2015). Cytospora from Ulmus pumila in northern China. Mycol. Prog. 14, 1-12. doi: 10.1007/s11557-015-1096-1

Zhu, H. Y., Pan, M., Bezerra, J. D. P., Tian, C. M., and Fan, X. L. (2020). Discovery of Cytospora species associated with canker disease of tree hosts from Mount Dongling of China. MycoKeys 62, 97-121. doi: 10.3897/mycokeys.62.47854
Zhu, H. Y., Tian, C. M., and Fan, X. L. (2018). Multigene phylogeny and morphology reveal Cytospora spiraeae sp. nov. (Diaporthales, Ascomycota) in China. Phytotaxa 338, 49-62. doi: 10.11646/phytotaxa.338.1.4

Zhuang, W. Y. (2005). Fungi of Northwestern China. New York, NY: Mycotaxon, Ltd.

Conflict of Interest: The authors declare that the research was conducted in the absence of any commercial or financial relationships that could be construed as a potential conflict of interest.

Copyright (c) 2021 Pan, Zhu, Tian, Huang and Fan. This is an open-access article distributed under the terms of the Creative Commons Attribution License (CC BY). The use, distribution or reproduction in other forums is permitted, provided the original author(s) and the copyright owner(s) are credited and that the original publication in this journal is cited, in accordance with accepted academic practice. No use, distribution or reproduction is permitted which does not comply with these terms. 